Realization of the danger of intense radio-wave fields has led, recently, to a need for their measurement. A method of calibrating field-strength meters for these measurements was shown in which the intense field was produced in the space between the two plates of a 'strip waveguide'. In this way a field of the necessary intensity was produced from a comparatively feeble source of power and was confined to the guide, where it was harmless.

Other exhibits showed what was being done in research concerned with rockets and artificial satellites. Observations of the Faraday and Doppler effects on the waves emitted from satellites had led to deductions about the total electron content of the ionosphere overhead. Observations of the orbits of satellites were being used to make deductions about the density of the upper atmosphere and its variation.

An experiment to investigate the electron density in the ionospheric $D$ region is to be performed in a rocket fired from Watheroo in Australia. This experiment will be done in collaboration with the University of Sheffield. The apparatus in the rocket will measure the parameters of a low-frequency wavefield set up above a transmitter radiating waves from the ground on a frequency near $200 \mathrm{kc} . / \mathrm{s}$. Part of the equipment was shown.
The Research Station is to collaborate with Canada and the United States in an experiment designed to investigate the upper side of the ionosphere. In this, satellites designed and launched by those working in the other countries will carry equipment to sound the ionosphere from above. The part of the Radio Research Station will be to receive telemetry from these satellites at Slough, Falkland Islands and Singapore, and to compare the results of the 'topside' sounding with the results of sounding made at these three places from the ground.

The Research Station is responsible for manning and running a station of the 'Minitrack' system set up by the Americans on a world-wide basis for the tracking of artificial satellites and the reception of their telemetry. The equipment is provided on loan by the Americans and is installed at a field site in Winkfield, about eleven miles from the Research Station. The visitors were taken there to see it. Measurements of position and records of telemetry made at this Station are sent back to America and are also available for the use of workers on the Station.

A World Data Centre for Rockets and Satellites, one of three, is run by the Station which is also responsible for tracking the position of the more important satellites for the use of optical and radio observers in Britain.

\title{
THE ROYAL AIRCRAFT ESTABLISHMENT, FARNBOROUGH
} HE open days held at the Royal Aircraft Estab-
lishment, Farnborough, during June 9 -10 were
the first for six years. (The annual Air Show is, of
course, that of the Society of British Aircraft Con-
structors, who hire the airfield for the occasion.)
They gave a vivid impression of an Establishment
that can afford to remain silent about its 56 famous
years of service to scientific aviation (except through
the single exhibit of a flying S.E.5a, the fighter
designed at Farnborough of which Britain built 5,000
in the First World War), presumably because the
present is so packed with excitement and achievement
in the Establishment's main fields of transport air-
craft, military aircraft, space, weapons, aircraft equipment and general research.

A central display hall, transformed from an aircraft hangar into a pavilion with flowers and fountains, summed up the whole display. It set out in its first illustrated stand the organization of the Royal Aircraft Establishment, with its headquarters at Farnborough, its second ultra-modern research centre and airfield at Bedford, and its well-equipped ranges for weapon trials. Subsequent stands, each devoted to one of the six main fields just noted, showed by models and highly informative backcloths how the different kinds of scientist and engineer in the Establishment make their different contributions to each. For example, study of transport aircraft problems was stated to include work on 'cabin conditioning', 'engine intake design', 'metal fatigue' and 'communications engineering' as four out of some thirty separate contributions-and similarly with the other fields. Two further stands showed the impressive range of major equipment for experimentation which the Fistablishment possesses to help it do its work, and the large-scale workshops, drawing-office and aircraft-servicing effort that lies behind the scientific achievements.

Both this central hall, and the 108 specialized scientific or technological exhibits, showed an Establishment pushing vigorously forward, with all its extraordinarily diverse activities concentrated on a few clearly defined objectives-to get air transport safer, cheaper, faster, more comfortable, more reliable, to get for the Army, Royal Navy and Royal Air Force a complete range of aircraft and weapons which will use the latest scientific advances to meet economically the needs of war as they are now envisaged, to develop continually improved aircraft equipment for navigation, reconnaissance, communications, power generation, automatic control and even landing, and to ensure that in spite of a late start Britain reaps the benefits of operations in space. Inquiries showed that the extent of 'space' activity, not only on the development of launching vehicles based on Blue Streak but also on the technology of satellites themselves, with special emphasis on a satellite system for world-wide communications, would almost justify a re-christening as the 'Royal Aircraft and Spacecraft Establishment'.

In advanced scientific research the variety of activity was astounding. For example, supersonic and hypersonic aerodynamics were to be expected, but the strength of the Farnborough school of lowspeed aerodynamic research was equally evident, and remains equally necessary. The complexity of its subject-matter was exemplified by a wind-tunnel investigation of the effect of ground proximity on the lift of an aircraft model with swivelling jets, after the manner of the Hawker P.1127 vertical-take-off strike aircraft. Equally the 'slender-delta' designs of supersonic airliner have demanded for the solution of 
their landing and take-off problems a new aerodynamics, the extension of which into the unsteady 'gust case' was exemplified by an exciting experiment in which balsa-wood models were catapulted across a 24-ft. wide jet of air and their response in roll and yaw recorded by ciné-camera.

Another flourishing research school is in physics and chemistry of materials. The physical mechanisms of metal fatigue, including the details of crack development under cyclic loading, are now, in the main, scientifically determined, and are being rapidly related to the fatigue-life estimation of aircraft structures, showing, as one surprising result, that increase of temperature can sometimes extend fatigue life, because crack propagation in each cycle may halt sooner if plastic working is facilitated. Research on new materials has uncovered some impressive carbons with good strength and zero permeability, some new methods of construction in plastics reinforced with fibre-glass to give a strength-to-weight ratio 2.4 times better than 100 tons/in. ${ }^{2}$ steel, and a range of promising organic syntheses aimed at lubricants and polymers with improved hightemperature stability.

In the electronic field, an important new method of determination of the effective mass of charge carriers in semi-conductors was demonstrated, using observations of Faraday rotation, which was also shown modulating a beam of infra-red radiation at audio-frequencies. Promising circuits were exhibited, aimed at using semi-conductors to convert variablefrequency power from an aircraft's alternators to constant frequency. Research on aerials included the study of logarithmic-spiral forms at microwave frequencies, and some elegant work on corona breakdown on aircraft aerials at altitude. In the electronic equipment field, the miniaturized telemetry equipment, for transmitting pressures and other data to ground during weapon trials, stood out particularly.

Servocontrol is a well-known Farnborough activity. In the manned-aireraft field, it was interesting to see an aircraft being flown with all-electric signalling between the pilot's stick and the control surfaces.
This is being used to facilitate a range of mancuvre demands. In the rocket field, the control of Black Knight by the swivelling of its two motors was demonstrated, together with equipment for stabilizing the attitude in space of the upper-atmosphereresearch rocket Skylark. Equipment for studying the possible gyro-stabilization of a communications satellite so that its aerials will always point towards the centre of the Earth was also exhibited.

Research aimed at navigation and guidance was shown in impressive volume and quality. The propagation of very-low-frequency waves (of length around $20 \mathrm{~km}$.) is now known to have remarkable stability as far as the antipodes even during magnetic storms, and research in a Comet aircraft flying from Farnborough has given good reasons to expect development of an airborne system for world-wide position determination within an error of at most $5 \mathrm{~km}$. using only six ground transmitters. Inertial navigation has also been making extraordinarily rapid progress, with the Royal Aircraft Establishment again active, its longer-term researches being aimed, it appears, mainly at reduction in costs. Other titbits in this field were a tantalizing startracking demonstration and a glimpse of the future for high-speed computers in air traffic control.

It would be impossible to do justice to this huge exhibition in a short article, although a brief mention of the fascinating stands relating to water-drop or ice-crystal impact on aircraft, to new wind-tunnel techniques for aeroelastic research, and to rocket techniques for aerodynamic research at very high speeds, can scarcely be resisted. The days ended with experimental flying displays, showing among other things how the British army of the future may receive its supplies without parachutes, by low-level drops of equipment on special shock-absorbing skids, and how flight research is adding to our knowledge of the physical characteristics, and the effects on aircraft, of atmospheric turbulence.

Mr. M. J. Lighthill and his staff at Farnborough can be warmly congratulated, both on the story that they have had to tell and on the manner of its telling. Peter Sanderson

\section{BRITISH BAKING INDUSTRIES RESEARCH ASSOCIATION NEW LABORATORY WING}

\begin{abstract}
A NEW laboratory wing at the Baking Industries Research Station, Chorleywood, was opened on April 27 by Mr. Trevor Bowen, honorary president of Barkers of Kensington, and a former master of the Worshipful Company of Bakers.

In declaring the new north wing open, Mr. Trevor Bowen recalled the early days of the Research Association in 1947, when it had few members and a staff of only three, and, to indicate his appreciation of the services rendered by the Research Association, Mr. Bowen made a most generous gift of one thousand guineas as a contribution towards research.

The facilities of the new wing have been made essential by the growth in the Association's membership and activities. The work of the Association has outgrown the extra accommodation made available in 1951, when the present west wing was opened, and the need for additional and improved facilities has been a pressing one for some time.
\end{abstract}

The new accommodation consists of a two-storey wing running northwards from, and linked to, the original building of Chorleywood Lodge, designed to blend with the existing buildings and erected at a cost of approximately $£ 40,000$, including equipment.

The main feature of the ground-floor is the pilotscale biscuit bakery and its associated laboratory. New pieces of equipment, built specially by members of the Research Association, are a model forced convection travelling oven by the Spooner Food Machinery Engineering Co., Ltd., and a De Vuurslag rotary biscuit cutter supplied by John Pelkman Engineering Co., Ltd. The biscuit section will thus have, virtually, a model biscuit plant which will enable the whole range of hard- and soft-dough biscuits to be studied. It is expected that this will enable previous work to be expanded on such problems of biscuit production as checking, or spontaneous cracking, in biscuits, on changes in biscuit dimensions 